\title{
Potassium channel inhibitors induce oxidative stress in breast cancer cells
}

\author{
Çağrı Öner ${ }^{1, \#,}$ Ertuğrul Çolak², Didem Turgut Coşan ${ }^{1 *}$
}

\begin{abstract}
Background: Antioxidant levels increase to protect cell homeostasis when oxidant generation is increased by drug or inhibitor treatment. If the oxidant-antioxidant equilibrium is disrupted, oxidative stress will occur.

Objectives: To determine the effects of various potassium channel inhibitors in the disruption of oxidant-antioxidant equilibrium in breast cancer cell lines with various phenotypes.

Methods: MCF-7 or MDA-MB-231 breast cancer cells were treated with tetraethylammonium chloride (5 mM; TEA), 4-aminopyridine (5 mM; 4-AP), margatoxin ( $25 \mathrm{nM}$; MgTX), or astemizole (200 nM; AST). After treatment, total antioxidant, oxidant, and oxidative stress levels were determined.

Results: Incubation with TEA, 4-AP, MgTX, and AST increased oxidative stress in both MCF-7 and MDA-MB-231 cells $(P<0.001)$. Specific inhibitors of calcium-activated potassium channels and ether á go-go 1-related potassium channels produce greater oxidative stress than other inhibitors in MCF-7 breast cancer cells, whereas in MDA-MB-231 cells, the nonselective channel inhibitor 4-AP produces the greatest oxidative stress.

Conclusions: Potassium channel inhibitors used in our study disrupted the antioxidant-oxidant equilibrium and increased oxidative stress in the cancer cell lines. Although all of the channel inhibitors increased oxidative stress in cells, TEA and AST were the most effective inhibitors in MCF-7 cells. 4-AP was the most effective inhibitor in MDA-MB-231 cells. Voltage-gated potassium channels are attractive targets for anticancer therapy, and their inhibitors may enhance the effects of anticancer drugs.
\end{abstract}

Keywords: 4-aminopyridine, astemizole, breast cancer, margatoxin, oxidative stress, tetraethylammonium chloride

The presence of a strong defence system prevents damage caused by reactive oxygen species (ROS), including free radical compounds, produced in an organism. The rate of formation of ROS and that of their destruction or termination must be kept in balance for cell survival. If this redox balance is disrupted, the increased levels of peroxides and free radicals causes harmful oxidative stress through damage to cellular components, including proteins, nucleic acids, carbohydrates, and lipids [1]. Oxidative stress is related to a wide variety of diseases, including neurodegenerative, inflammatory, and cardiovascular diseases, allergies, immune system dysfunctions, diabetes, aging, and cancer [1]. Oxidative stress is thought to have a tumor suppressor effect in normal cells and is considered an important factor in tumor development.

*Correspondence to: Didem Turgut Coşan, Department of Medical Biology, Medical Faculty, Eskişehir Osmangazi University, Eskişehir 26480, Turkey, e-mail: dcosan@ogu.edu.tr

"Present address: Department of Medical Biology and Genetics, Maltepe University, İstanbul 34857, Turkey

'Department of Medical Biology, Medical Faculty, Eskişehir Osmangazi University, Eskişehir 26480, Turkey

2Department of Biostatics and Bioinformatics, Medical Faculty, Eskişehir Osmangazi University, Eskişehir 26480, Turkey

(c) (1) ()๑ ( 2017 Çağrı Öner, Ertuğrul Çolak, Didem Turgut Coşan

This Work is licensed under Creative Common License 
Various signaling pathways can regulate the metabolism of ROS, and these pathways are linked to tumorigenesis [2]. Studies in vivo and in vitro have shown that antioxidant systems play a key role by activating transcription factors to protect the systems against free radicals, which play a role as secondary messengers in intracellular signaling [2]. ROS can promote tumor initiation and development, such as proliferation via signaling cascades, avoidance of apoptosis, invasion, metastasis, and angiogenesis $[1,2]$. During any disruption of the oxidant-antioxidant equilibrium, free radicals and ROS quickly become toxic, and the oxidative stress damages DNA and reduces apoptosis. If this situation cannot be treated quickly, normal cells may become cancerous and begin to proliferate, followed by tumor metastasis [3].

Cancer cells produce free radicals and soluble mediators, such as metabolites of arachidonic acid, cytokines, and chemokines, which produce further ROS [4]. Furthermore, cancer cells are characterized by increased aerobic glycolysis (Warburg effect) and are subjected to high levels of oxidative stress $[2,4,5]$. High ROS levels are observed in cancer cells as a consequence of the regulation of metabolic and signaling disruptions affecting cellular metabolism [2, 6]. Cancer cells encounter high levels of ROS, especially at early stages of tumor development $[2,6]$. ROS levels can be resisted by elevated antioxidant mechanisms [5, 7]. In the presence of high ROS levels, malignant cell phenotypes, such as proliferation, immortality, angiogenesis, invasion, and metastasis, have been observed $[2,7]$.

Voltage-gated potassium channels (VGPC; Kv) are heteromultimeric proteins that show various channel structures, including a single ion-conducting passage and sensor or toxinbinding region [8]. VGPCs contribute to various physiological functions, and they are expressed in various tumor types $[9,10]$. The various types of potassium $(\mathrm{K})$ channels, including calcium-activated $\mathrm{K}$ channels $\left(\mathrm{K}_{\mathrm{Ca}}\right)$ and ATP-sensitive $\mathrm{K}$ channels $\left(\mathrm{K}_{\text {ATP }}\right)$ show altered expression in various cell types, especially tumor cells [11]. Overexpression of VGPCs is correlated with tumorigenesis. The first ion channel with proven oncogenic potential was Kv10.1 or ether á go-go 1 (Eag 1), which can be detected in approximately $70 \%$ of human tumor biopsies of diverse origin $[11,12]$. Furthermore, VGPCs regulate apoptosis, proliferation, angiogenesis, invasion, and metastasis in various cancers $[13,14]$.

Testing VGPC inhibitors as a breast cancer treatment is motivated by the observation that breast cancer chemotherapeutic drugs inhibited the activity of VPGCs during cancer treatment [10]. VGPC inhibitors block the activity of potassium channels and thus they also inhibit physiological functions [15]. Tetraethylammonium chloride (TEA) inhibits $\mathrm{K}_{\mathrm{Ca}}$ [16]; 4-aminopyridine (4-AP) is a nonselective
VGPC inhibitor. Margatoxin (MgTX), Stichodactyla toxin (ShK), and charybdotoxin are among the peptide inhibitors of Kv1.3 [17]. MgTX is a type of scorpion toxin that inhibits all VGPCs but is more potent for Kv1.3 and Kv1.6 channels [18]. Although astemizole (AST) targets ATP-binding cassette transporters and histamine receptors, as well as binding to chromatin, it also inhibits several VGPCs, especially Eag-related gene (Erg) [19].

The synergistic effect of TEA and quercetin, an antioxidant and anticancer drug, inhibited the overexpression of $\mathrm{K}_{\mathrm{Ca}}$ in and proliferation of bladder cancer cells [20]. The proliferation of breast cancer cells was inhibited by using TEA to block Kv1.3 channels [21]. 4-AP inhibits both proliferation of tumor cells and outwardly rectifying potassium channels in U87 and A172 cells [22]. In a U87-MG xenograft model of glioma in nude mice, injecting cells treated with selective inhibitors of VPGCs or $\mathrm{K}_{\text {ATPS }}$, 4-AP, TEA, or glibenclamide significantly inhibited the proliferation of the human U87-MG cells, blocking the growth of the VGPC inhibitor-treated cells at the $\mathrm{G} 0 / \mathrm{G} 1$ phase by $50 \%$, and induced apoptosis $[11,23]$. 4-AP inhibited proliferation of MCF10A cells by anticancerspecific mechanisms [24]. MgTX inhibited the proliferation of A549 lung adenocarcinoma cells by blocking Kv1.3 in vivo. Furthermore, MgTX reduced tumor volumes in vitro [13]. MgTX or short hairpin RNA of Kv1.3 blocked proliferation of A549 human lung adenocarcinoma cells in vitro, and intratumoral injection of MgTX reduced tumor volume by $75 \%$ in vivo [13]. The antiproliferative effect of MgTX was confirmed in a model of orthotropic melanoma using B16F10 cells in vivo [25]. AST is an antihistamine and has been suggested as an anticancer drug $[19,26]$. AST potently inhibits Eag1 and human Erg potassium channels. AST has antiproliferative effects in vivo and in vitro, especially in Eag1-possessing tumor cells, such as breast cancer and melanoma cells [19,27]. The antiproliferative effect of AST might be the result of targeting several proteins involved in cancer, such as histamine receptor 1, P-glycoprotein, Eag1, and Erg [28]. AST inverted doxorubicin resistance in leukemia cells [19]. Inhibition by imipramine and AST reduced growth of Eag1-driven small cell lung cancer and neuroendocrine tumor cells in vivo [29]. AST decreased proliferation and induced apoptosis of cervical cancer cells by inhibiting Eag1 [26]. Furthermore, AST and vitamin D (calcitriol) reduced tumor volume by $85 \%$ in mice with a xenograft of T-47D breast cancer cells or with a primary breast cancer-derived cell culture [11, 30].

Cell growth, proliferation, and induction or inhibition of apoptosis is dependent on the amount of ROS when the VGPC inhibitors are administered to cancer cells [31]. Initiation, promotion, and progression steps cause cells to become cancerous. ROS might be related in all molecular mechanisms 
of these 3 steps of tumorigenesis [7]. ROS are thought to be both initiators and promoters because they act as mutagenic agents and can interfere with signaling pathways. Permanent stimulus of proliferation is a common feature in tumor cells and is often associated with structural activation of signaling pathways associated with cell growth. The role of ROS in cell proliferation has been widely reported in the literature. Addition of $\mathrm{H}_{2} \mathrm{O}_{2}$ at high concentrations causes oxidative damage to macromolecules, leading to cell death or aging, while low doses can stimulate cell proliferation in a few cell lines [32]. Reduced antioxidant capacity is an index of excessive oxidative stress. Antioxidant status is an indicator of redox homeostasis [33]. Some peptides protect cells from accumulation of ROS. For example, polyamine-depleted cells accumulate ROS, develop an apoptotic phenotype, and apoptosis occurs after incubation in polyamine-deficient medium [34]. On the one hand, addition of spermine to growth media can cause a marked decrease in ROS accumulation and some protection against cell death [35]. On the other hand, metabolism of polyamines can produce $\mathrm{H}_{2} \mathrm{O}_{2}$, and so the mechanisms are complex [36].

Breast cancer is the most commonly diagnosed cancer in women worldwide. Oxidative stress has been shown to participate in the structural modification of estrogen and progesterone receptors, altering clinical characteristics [1]. The roles of ROS and oxidative stress in breast cancer etiology and progression are being progressively elucidated [7]. The important role of VGPCs in breast cancer and its metastasis is known. We know from previous studies that increasing the oxidative stress might enforce apoptosis in cancer cells. In the present study, we aimed to increase oxidative stress by inhibiting the active VGPCs in lines of benign and malignant breast cancer cells. Secondarily, we aimed to determine which inhibitor was more effective on VGPCs in the breast cancer cell lines. We sought to determine whether inhibition of oxidative stress (the disruption of oxidant-antioxidant equilibrium) is related to the benign or malignant phenotype of the breast cancer cell lines by comparing the relative effect of the VGPC inhibitors.

\section{Materials and methods}

\section{Cell culture and application of inhibitors}

MCF-7 and MDA-MB-231 cells were purchased from the American Type Culture Collection (ATCC), and the cells were incubated at $37^{\circ} \mathrm{C}$ with $5 \% \mathrm{CO}_{2}$ in Dulbecco's modified Eagle's medium (DMEM; Gibco) containing $100 \mathrm{U} / \mathrm{mL}$ penicillin/ streptomycin (Gibco) and 10\% fetal bovine serum (FBS) (Gibco).

Before application of inhibitors, the MCF-7 and MDAMB-231 cells were incubated in 6-well plates (Orange
Scientific, Belgium) to grow the cells to $80 \%$ confluence. TEA (5 mM), 4-AP (5 mM), MgTX (25 nM), and AST (200 nM) were obtained from Sigma-Aldrich. To determine the total antioxidant and oxidant levels of breast cancer cells, the cells were harvested from 6-well plates after $48 \mathrm{~h}$.

\section{Determination of the total antioxidant and oxidant levels}

Total antioxidant and oxidant levels were measured by using an automated method. Total Antioxidant Status assay kit (TAS; Rel Assay Diagnostics, Turkey) was used to determine the total antioxidant levels in MCF-7 and MDA-MB-231 breast cancer cells. The principle of the total antioxidant assay kit is that antioxidants in the sample reduce dark blue-green-colored 2,2'-azino-bis(3-ethylbenzothiazoline-6-sulfonate) (ABTS) radical to a colorless reduced form of ABTS. The change of absorbance at $660 \mathrm{~nm}$ is related to the total antioxidant level of the sample. The assay is calibrated with a stable antioxidant standard solution, which is conventionally named as Trolox equivalent, a vitamin $\mathrm{E}$ analog.

Total Oxidant Status assay kit (TOS; Rel Assay Diagnostics) was used to determine the total oxidant levels of MCF-7 and MDA-MB-231 breast cancer cells. The principle of the total oxidant assay kit is that oxidants present in the sample oxidize the ferrous ion-chelator complex to ferric ion. The oxidation reaction is prolonged by enhancer molecules, which are abundantly present in the reaction medium. The ferric ion forms a colored complex with a chromogen in an acidic medium. The color intensity, which can be measured spectrophotometrically, is related to the total amount of oxidant molecules present in the sample. The assay was calibrated with $\mathrm{H}_{2} \mathrm{O}_{2}$, and the results are expressed in $\mu$ mole $\mathrm{H}_{2} \mathrm{O}_{2}$ equiv/L. The oxidative stress in MCF-7 and MDA-MB-231 cells treated with inhibitor was calculated using the obtained total antioxidant and oxidant levels. The results are reported as arbitrary units.

\section{Oxidative stress}

The oxidative stress is calculated as follows:

(Total oxidant level/total antioxidant level) $\times 100$

\section{Statistical analysis}

A normal distribution of continuous variables was determined using a Kolmogorov-Smirnov test. Comparisons between 
groups of normally distributed variables were evaluated using a one-way analysis of variance. A Tukey honest significant difference test was used for multiple comparisons. The data are reported as the mean \pm standard deviation. Differences were considered statistically significant at $P<0.001$. All analyses were performed using IBM SPSS Statistics for Windows (version 21.0).

\section{Results}

Optimal concentrations of TEA (5 mM), 4-AP (5 mM), $\operatorname{MgTX}(25 \mathrm{nM})$, and AST (200 nM) for both breast cancer cell lines MCF-7 and MDA-MB-231 were used according to levels determined in previous studies [13, 19, 20, 24, $27,30]$. Compared with the control group, total antioxidant levels were significantly decreased in MCF-7 cells treated with $5 \mathrm{mM}$ 4-AP, $25 \mathrm{nM}$ MgTX, or $200 \mathrm{nM}$ AST, while MCF-7 cells treated with $5 \mathrm{mM}$ TEA showed a significant increase (Figure 1A). The total oxidant level was significantly increased compared with the control group in MCF-7 cells treated with $5 \mathrm{mM}$ TEA, $5 \mathrm{mM}$ 4-AP, $25 \mathrm{nM} \mathrm{MgTX,}$ or $200 \mathrm{nM}$ AST (Figure 1B). According to the formula (Eq. 1), MCF-7 cells treated with $5 \mathrm{mM}$ TEA, $5 \mathrm{mM}$ 4-AP, $25 \mathrm{nM} \mathrm{MgTX}$, and $200 \mathrm{nM}$ AST showed a significant increase in oxidative stress compared with the control group (Figure 1C).

In MDA-MB-231 breast cancer cells, the total antioxidant levels were increased significantly compared with the control group after treatment with $5 \mathrm{mM}$ TEA, $5 \mathrm{mM} 4-\mathrm{AP}, 25 \mathrm{nM}$ MgTX, or 200 nM AST (Figure 2A). Furthermore, the total oxidant levels were increased significantly compared with the control group in MDA-MB-231 cells treated with $5 \mathrm{mM}$ TEA, $5 \mathrm{mM}$ 4-AP, $25 \mathrm{nM} \mathrm{MgTX}$, or $200 \mathrm{nM}$ AST (Figure 2B). According to the formula (Eq. 1), the oxidative stress was increased significantly compared with the control group in MDA-MB-231 cells treated with $5 \mathrm{mM}$ TEA, $5 \mathrm{mM} 4-\mathrm{AP}$, $25 \mathrm{nM}$ MgTX, or $200 \mathrm{nM}$ AST (Figure 2C).
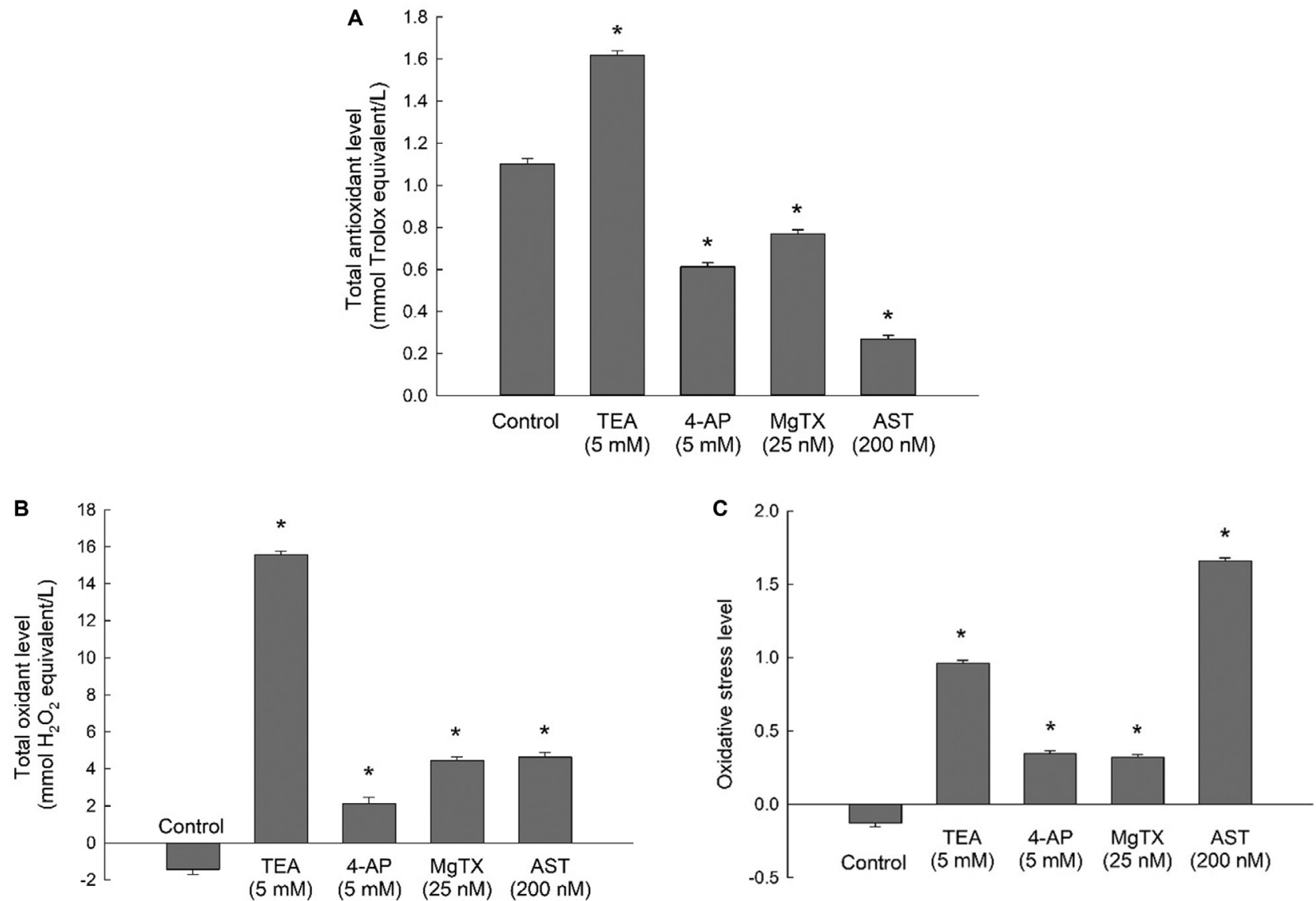

Figure 1. The effects of voltage-gated potassium channel inhibitors on the total antioxidant, oxidant, and oxidative stress levels of MCF-7 breast cancer cells. (A) The effects of tetraethyl ammonium chloride (TEA), 4-aminopyridine (4-AP), margatoxin (MgTX), or astemizole (AST) on the total antioxidant levels in MCF-7 cells. (B) The effects of TEA, 4-AP, MgTX, or AST on the total oxidant level in MCF-7 cells. (C) The effects of TEA, 4-AP, MgTX, or AST on the oxidative stress level in MCF-7 cells. $n=7$ for each experiment group; error bars $=10$ standard deviations. ${ }^{*} P<0.001$ 

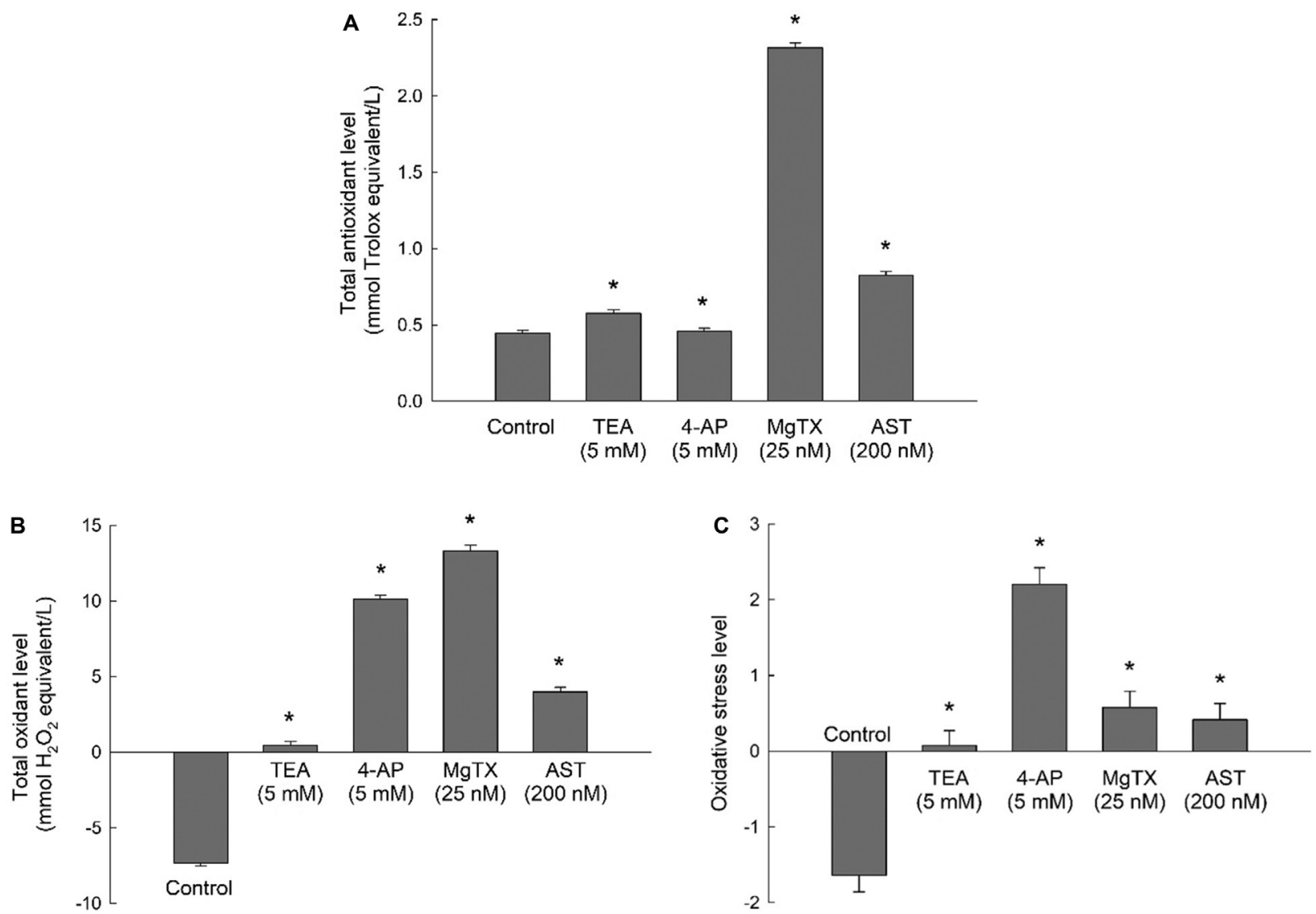

Figure 2. The effects of voltage-gated potassium channel inhibitors on the total antioxidant, oxidant and oxidative stress levels of MDA-MB-231 breast cancer cells. (A) The effects of tetraethyl ammonium chloride (TEA), 4-aminopyridine (4-AP), margatoxin (MgTX), and astemizole (AST) on the total antioxidant levels in MDA-MB-231 cells. (B) The effects of TEA, 4-AP, MgTX, and AST on the total oxidant level in MDA-MB-231 cells. (C) The effects of TEA, 4-AP, MgTX, and AST on the oxidative stress level of MDA-MB-231 cells. $\mathrm{n}=7$ for each experiment group; error bars $=10$ standard deviations; ${ }^{* P}<0.001$

\section{Discussion}

We found that all VGPC inhibitors (AST, TEA, 4-AP, and MgTX in decreasing order of effectiveness) increased oxidative stress in the MCF-7 human mammary carcinoma or breast cancer cells. MgTX, 4-AP, and AST decreased total antioxidant levels in MCF-7 cells and increased the total oxidant levels. TEA increased both levels dramatically, but did not increase overall oxidative stress as much as AST in MCF-7 cells. To our knowledge, there is no literature regarding the effects on oxidative stress in MCF-7 cells by inhibition of VGPCs with 4-AP and TEA. MgTX induces an increase on ROS levels by blocking Kv1.3 in lymphocytes [37]. Inhibitors of mitochondrial Kv1.3 (mtKv1.3), such as MgTX, have the ability to induce increases in ROS levels in peripheral blood mononuclear cells, suggesting that ROS levels can be increased in cancer cells $[17,11]$. We found that MgTX induces oxidative stress in MCF-7 cells, suggesting the involvement of Kv1.3 channels. Our present results are consistent with those of Jakhar et al., who showed that AST increases ROS production in MCF-7 breast cancer cells [38]. We also showed that inhibiting $\mathrm{K}_{\mathrm{Ca}}$ increased both antioxidant and oxidant levels in MCF-7 cells. TEA was the most effective inducer of total oxidant and antioxidant levels in MCF-7 cells. In this case, the oxidant-antioxidant equilibrium was disrupted and oxidative stress occurred in MCF-7 cells treated with TEA. Woodfork et al. found that of 9 potassium channel antagonists, 5 antagonists produced a concentration-dependent inhibition of MCF-7 proliferation with no evidence of cytotoxicity following a 3-day or 5-day exposure to the drug. The half-maximal inhibitory concentration $\left(\mathrm{IC}_{50}\right)$ values for the 5 antagonists were as follows: quinidine: $25 \mu \mathrm{M}$; glibenclamide: $50 \mu \mathrm{M}$; linogliride: $770 \mu \mathrm{M}$; 4-AP: $1.6 \mathrm{mM}$; and TEA: $5.8 \mu \mathrm{M}$, as estimated from their respective concentration-response curves. Four other potassium channel blockers, including charybdotoxin $(200 \mathrm{nM})$, iberiotoxin $(100 \mathrm{nM}), \operatorname{MgTX}(10 \mathrm{nM})$, and apamin $(500 \mathrm{nM})$, were tested at supramaximal channel-blocking concentrations; they had no effect on MCF-7 cell proliferation, 
viability, or cell cycle distribution. Woodfork et al. concluded that only inhibition of ATP-sensitive potassium channels in MCF-7 reversibly arrests the cells in the G0/G1 phase of the cell cycle, inhibiting proliferation [39]. We used concentrations consistent with or greater than those used in this study. The inhibitor most effective in increasing total oxidant and antioxidant levels in MCF-7 cells in the present study (namely, TEA) is less selective for particular channels than MgTX and most likely acts on large-conductance $\mathrm{K}_{\mathrm{Ca}}$ channels, but is considerably less potent than peptide inhibitors and AST. Further work is necessary to identify the channels responsible for both proliferation [40, 41] and redox balance in MCF-7 cells. It may be that various potassium channels exert their influences on tumor cells through distinctly different mechanisms.

In MDA-MB-231 breast cancer cells, all VGPC inhibitors increased not only total antioxidant levels, but also total oxidant levels, although TEA had much less effect in MDA-MB-231 cells than it did in MCF-7 cells. The effect of 4-AP on oxidative stress levels in these cells was remarkable. Although the total antioxidant level is almost the same as in the control group, MDA-MB-231 cells treated with 4-AP had the highest level of oxidative stress, whereas TEA had less effect on oxidative stress than it did in MCF-7 cells. 4-AP is poorly selective and probably acts most strongly on rapidly inactivating, voltage-gated Kv1.3 channels. MgTX, 4-AP, and AST also increased both antioxidant and oxidant levels. When oxidant-antioxidant levels are considered, oxidative stress levels were found to be increased in MDA-MB-231 cells on treatment with all inhibitors. We speculate that the reason for this increase is the cellular response for homeostasis. Secondary messengers, such as ROS, stimulate VGPCs, and cellular homeostasis is disrupted. When VGPCs are inhibited, channel activity would be blocked and ROS will be increased. The increase of ROS would cause an increase in total oxidant levels and oxidative stress. Because of this disrupted antioxidant-oxidant ratio, oxidative stress was seen in MCF-7 and MDA-MB-231 breast cancer cells. To our knowledge, there are no published studies on the inhibition of VGPCs by TEA, 4-AP, MgTX, or AST and their effects on oxidative stress in MDA-MB-231 cells, although one study using specific small interfering RNAs and blockers, including 1-(2-chlorophenyl) diphenylmethyl-1H-pyrazole (TRAM-34) and clotrimazole, has shown that intermediate-conductance calcium-activated potassium $\mathrm{K}_{\mathrm{Ca}}$ (SK4) channels suppress cell proliferation, migration, and the epithelial-mesenchymal transition, and that these channels are less prevalent on MCF-7 cells [41].

We showed that oxidative stress in cancer cells can be regulated by ion channel inhibition. Oxidative stress may harm cancer cells. VGPC inhibitors caused oxidative stress in breast cancer cells, and so VGPCs represent a potential therapeutic target. More detailed studies are required to support this hypothesis.
To determine the detailed roles of VGPC inhibitors on ROS in cancer cells, further methods such as measurement of superoxide dismutase, flow cytometry studies after loading with redox sensitive dyes, or microscopy studies on single cells could be used. Our present study was limited by the observation of only the total antioxidant and oxidant levels in breast cancer cells while VGPCs were inhibited. Other limitations include the lack of specificity and the potency of the agents producing the highest levels of oxidative stress in this study.

\section{Conclusion}

The data obtained in the present study showed that potassium channel inhibitors, especially AST and TEA, increased oxidative stress in MCF-7 cells, which have benign, early stage, and poorly invasive characteristics. Although all potassium channel inhibitors increased oxidative stress in MDA-MB-231 cells, which have greater malignant potential, advanced stage, and metastatic characteristics than MCF-7 cells, the nonselective channel inhibitor 4-AP had the greatest effect in MDA-MB-231 cells, and much more so than TEA, suggesting more importance of $\mathrm{Kv} 1.3$ than $\mathrm{K}_{\mathrm{Ca}}$ (and Erg) channels for oxidative stress in cells with greater malignant potential and vice versa. The present results suggest that VGPCs are an attractive target for anticancer therapy. Further studies are needed to clarify the use of oxidant and antioxidant levels as markers of oxidative stress in breast and other cancers, determine the precise roles of VGPCs in oxidative stress in breast cancer, and and identify the channels responsible, and whether through their effects on oxidative stress, VGPC inhibitors can enhance the effect of anticancer drugs.

Author contributions. ÇÖ and DTC substantially contributed to the conception and design of the study. ÇÖ and DTC substantially contributed to the acquisition of data, including conducting the experiments and analysis and interpretation of the results. EÇ analyzed and interpreted the results statistically. ÇÖ drafted the manuscript, and all authors critically revised it, approved the final version, and take responsibility for the statements made in the article.

Acknowledgments. This research did not receive any specific grant from funding agencies in the public, commercial, or not-for-profit sectors.

Conflict of interest statement. The corresponding author (ÇÖ) has completed and submitted the International Committee of Medical Journal Editors (ICMJE) Uniform Disclosure Form for Potential Conflicts of Interest on behalf of all authors. None of the authors disclose any conflict of interest. 


\section{References}

[1] Sosa V, Moline T, Somoza R, Paciucci R, Kondoh H, ME LL. Oxidative stress and cancer: an overview. Ageing Res Rev. 2013; 12:376-90.

[2] Gorrini C, Harris IS, Mak TW. Modulation of oxidative stress as an anticancer strategy. Nat Rev Drug Discov. 2013; 12:931-47.

[3] Gupta R, Sikka SC. Prostate cancer and oxidative stress. In: Laher I, editor. Systems biology of free radicals and antioxidants. Berlin: Springer-Verlag; 2014. p. 2835-50.

[4] Federico A, Morgillo F, Tuccillo C, Ciardiello F, Loguercio C. Chronic inflammation and oxidative stress in human carcinogenesis. Int J Cancer. 2007; 121:2381-6.

[5] Cairns RA, Harris IS, Mak TW. Regulation of cancer cell metabolism. Nat Rev Cancer. 2011; 11:85-95.

[6] Diehn M, Cho RW, Lobo NA, Kalisky T, Dorie MJ, Kulp AN, et al. Association of reactive oxygen species levels and radioresistance in cancer stem cells. Nature. 2009; 458:780-3.

[7] Hecht F, Pessoa CF, Gentile LB, Rosenthal D, Carvalho DP, Fortunato RS. The role of oxidative stress on breast cancer development and therapy. Tumour Biol. 2016; 37:4281-91.

[8] Hernandes MS, Troncone LRP. Glycine as a neurotransmitter in the forebrain: a short review. J Neural Transm (Vienna). 2009; 116:1551-60.

[9] Leanza L, Zoratti M, Gulbins E, Szabo I. Mitochondrial ion channels as oncological targets. Oncogene. 2014; 33:5569-81.

[10] Villalonga N, Ferreres JC, Argilés JM, Condom E, Felipe A. Potassium channels are a new target field in anticancer drug design. Recent Pat Anticancer Drug Discov. 2007; 2:212-23.

[11] Leanza L, Managò A, Zoratti M, Gulbins E, Szabo I. Pharmacological targeting of ion channels for cancer therapy: In vivo evidences. Biochim Biophys Acta. 2016; 1863:1385-97.

[12] Urrego D, Tomczak AP, Zahed F, Stühmer W, Pardo LA. Potassium channels in cell cycle and cell proliferation. Philos Trans R Soc Lond B Biol Sci. 2014; 369:20130094, doi: 10.1098/rstb.2013.0094.

[13] Jang SH, Choi SY, Ryu PD, Lee SY. Anti-proliferative effect of Kv1.3 blockers in A549 human lung adenocarcinoma in vitro and in vivo. Eur J Pharmacol. 2011; 651:26-32.

[14] Borowiec AS, Hague F, Harir N, Guénin S, Guerineau F, Gouilleux F, et al. IGF-1 activates hEAG $\mathrm{K}^{+}$channels through an Akt-dependent signaling pathway in breast cancer cells: role in cell proliferation. J Cell Physiol. 2007; 212:690-701.

[15] Brevet M, Ahidouch A, Sevestre H, Merviel P, El Hiani Y, Robbe M, et al. Expression of $\mathrm{K}^{+}$channels in normal and cancerous human breast. Histol Histopathol. 2008; 23:965-72.

[16] So EC, Huang Y-M, Hsing C-H, Liao Y-K, Wu S-N. Arecoline inhibits intermediate-conductance calcium-activated potassium channels in human glioblastoma cell lines. Eur J Pharmacol. 2015; 758:177-87.

[17] Leanza L, Venturini E, Kadow S, Carpinteiro A, Gulbins E, Becker KA. Targeting a mitochondrial potassium channel to fight cancer. Cell Calcium. 2015; 58:131-8.

[18] Hu L, Pennington M, Jiang Q, Whartenby KA, Calabresi PA. Characterization of the functional properties of the voltage-gated potassium channel Kv1.3 in human CD4+ T lymphocytes. J Immunol. 2007; 179:4563-70.

[19] García-Quiroz J, Camacho J. Astemizole: an old anti-histamine as a new promising anti-cancer drug. Anticancer Agents Med Chem. 2011; 11:307-14.
[20] Kim Y, Kim WJ, Cha EJ. Quercetin-induced growth inhibition in human bladder cancer cells is associated with an increase in $\mathrm{Ca}^{2+}$-activated $\mathrm{K}^{+}$channels. Korean J Physiol Pharmacol. 2011; 15:279-83.

[21] Jang SH, Kang KS, Ryu PD, Lee SY. Kv1.3 voltage-gated $\mathrm{K}^{+}$channel subunit as a potential diagnostic marker and therapeutic target for breast cancer. BMB Rep. 2009; 42:535-9.

[22] Chin LS, Park CC, Zitnay KM, Sinha M, DiPatri AJ Jr., Perillán P, et al. 4-Aminopyridine causes apoptosis and blocks an outward rectifier $\mathrm{K}^{+}$channel in malignant astrocytoma cell lines. J Neurosci Res. 1997; 48:122-7.

[23] Ru Q, Tian X, Wu YX, Wu RH, Pi MS, Li CY. Voltage-gated and ATP-sensitive $\mathrm{K}^{+}$channels are associated with cell proliferation and tumorigenesis of human glioma. Oncol Rep. 2014; 31:842-8.

[24] Liu J, Feng S, Zhang L, Wu Z, Chen Q, Cheng W, et al. [Expression and properties of potassium channels in human mammary epithelial cell line MCF10A and its possible role in proliferation]. Sheng Li Xue Bao [Acta Physiologica Sinica]. 2010; 62:203-9. [in Chinese, English abstract].

[25] Leanza L, Henry B, Sassi N, Zoratti M, Chandy KG, Gulbins E, et al. Inhibitors of mitochondrial Kv1.3 channels induce Bax/Bak-independent death of cancer cells. EMBO Mol Med. 2012; 4:577-93.

[26] de Guadalupe Chávez-López M, Hernández-Gallegos E, Vázquez-Sánchez AY, Gariglio P, Camacho J. Antiproliferative and proapoptotic effects of astemizole on cervical cancer cells. Int J Gynecol Cancer. 2014; 24:824-8.

[27] Ouadid-Ahidouch H, Le Bourhis X, Roudbaraki M, Toillon RA, Delcourt P, Prevarskaya N. Changes in the $\mathrm{K}^{+}$current-density of MCF-7 cells during progression through the cell cycle: possible involvement of a h.ether-á-gogo $\mathrm{K}^{+}$channel. Receptors Channels. 2001; 7:345-56.

[28] Breier A, Gibalova L, Seres M, Barancik M, Sulova Z. New insight into p-glycoprotein as a drug target. Anticancer Agents Med Chem. 2013; 13:159-70.

[29] Jahchan NS, Dudley JT, Mazur PK, Flores N, Yang D, Palmerton A, et al. A drug repositioning approach identifies tricyclic antidepressants as inhibitors of small cell lung cancer and other neuroendocrine tumors. Cancer Discov. 2013; 3:1364-77.

[30] García-Quiroz J, García-Becerra R, Santos-Martínez N, Barrera $\mathrm{D}$, Ordaz-Rosado D, Avila E, et al. In vivo dual targeting of the oncogenic Ether-á-go-go-1 potassium channel by calcitriol and astemizole results in enhanced antineoplastic effects in breast tumors. BMC Cancer. 2014; 14:745, doi: 10.1186/1471-2407-14-745.

[31] Venturini E. Kv1.3 inhibitors in the treatment of glioma and melanoma [doctoral dissertation]. Germany: Universität Duisburg-Essen; 2015.

[32] Stone JR, Yang S. Hydrogen peroxide: a signaling messenger. Antioxid Redox Signal. 2006; 8:243-70.

[33] Dyugovskaya L, Lavie P, Lavie L. Increased adhesion molecules expression and production of reactive oxygen species in leukocytes of sleep apnea patients. Am J Respir Crit Care Med. 2002; 165:934-9.

[34] Chattopadhyay MK, Tabor CW, Tabor H. Polyamine deficiency leads to accumulation of reactive oxygen species in a spe $2 \Delta$ mutant of Saccharomyces cerevisiae. Yeast. 2006; 23:751-61.

[35] Hermann A, Sitdikova GF, Weiger TM. Oxidative stress and maxi calcium-activated potassium (BK) channels. Biomolecules. 2015; 5:1870-911. 
[36] Agostinelli E, Tempera G, Viceconte N, Saccoccio S, Battaglia V, Grancara $S$, et al. Potential anticancer application of polyamine oxidation products formed by amine oxidase: a new therapeutic approach. Amino Acids. 2010; 38:353-68.

[37] Szabó I, Bock J, Grassmé H, Soddemann M, Wilker B, Lang F, et al. Mitochondrial potassium channel Kv1.3 mediates Bax-induced apoptosis in lymphocytes. Proc Natl Acad Sci U S A. 2008; 105:14861-6.

[38] Jakhar R, Paul S, Bhardwaj M, Kang SC. Astemizole-Histamine induces Beclin-1-independent autophagy by targeting p53-dependent crosstalk between autophagy and apoptosis. Cancer Lett. 2016; 372:89-100.

[39] Woodfork KA, Wonderlin WF, Peterson VA, Strobl JS. Inhibition of ATP-sensitive potassium channels causes reversible cell-cycle arrest of human breast cancer cells in tissue culture. J Cell Physiol. 1995; 162:163-71.

[40] Ouadid-Ahidouch H, Roudbaraki M, Delcourt P, Ahidouch A, Joury N, Prevarskaya N. Functional and molecular identification of intermediate-conductance $\mathrm{Ca}^{2+}$-activated $\mathrm{K}^{+}$channels in breast cancer cells: association with cell cycle progression. Am J Physiol Cell Physiol. 2004; 287:C125-34.

[41] Zhang P, Yang X, Yin Q, Yi J, Shen W, Zhao L, et al. Inhibition of SK4 potassium channels suppresses cell proliferation, migration and the epithelial-mesenchymal transition in triple-negative breast cancer cells. PLoS One. 2016; 11:e0154471, doi: 10.1371/journal. pone.0154471. 